\title{
Orbita ed effemeride del pianeta (264) Libussa.
}

Il Prof. Millosevich che mi ha ceduta la continuazione dei suoi calcoli su Libussa, aveva ottenuto per ciascuna delle tre prime opposizioni di questo pianeta (r886-r888-1889) un sistema di elementi osculatori. Io ho introdotto un luogo normale del 1890 , ottenendo cosi di ben rappresentare un insieme di osservazioni abbracciante un arco eliocentrico di circa $280^{\circ}$. Calcolate furono, secondo il solito, le perturbazioni di Giove e di Saturno.

Epoca ed osculazione r89 I Novembre 7.0 t. m. Berlino.

$$
\begin{aligned}
& M=26^{\circ} 59^{\circ} 29^{\prime \prime} \text { I } \\
& \omega=33^{6} \quad 14 \quad 0.4 \\
& \delta=\begin{array}{rrr}
49 & 57 & 12.6
\end{array} \quad 1890.0 \\
& i=102644.5 \\
& \varphi=7^{\circ} 47^{\circ} 7^{\prime \prime 2} \\
& x=[9.995776] r \cdot \sin \left(v+115^{\circ} 42^{\prime} 5^{2} .6\right) \\
& y=[9.937986] r \cdot \sin (v+3020 \text { 10.6) } \\
& z=[9.713816] r \cdot \sin (v+121841.1)
\end{aligned}
$$

Luoghi per $x^{\text {h }}$ Berlino, riferiti all' equinozio vero.

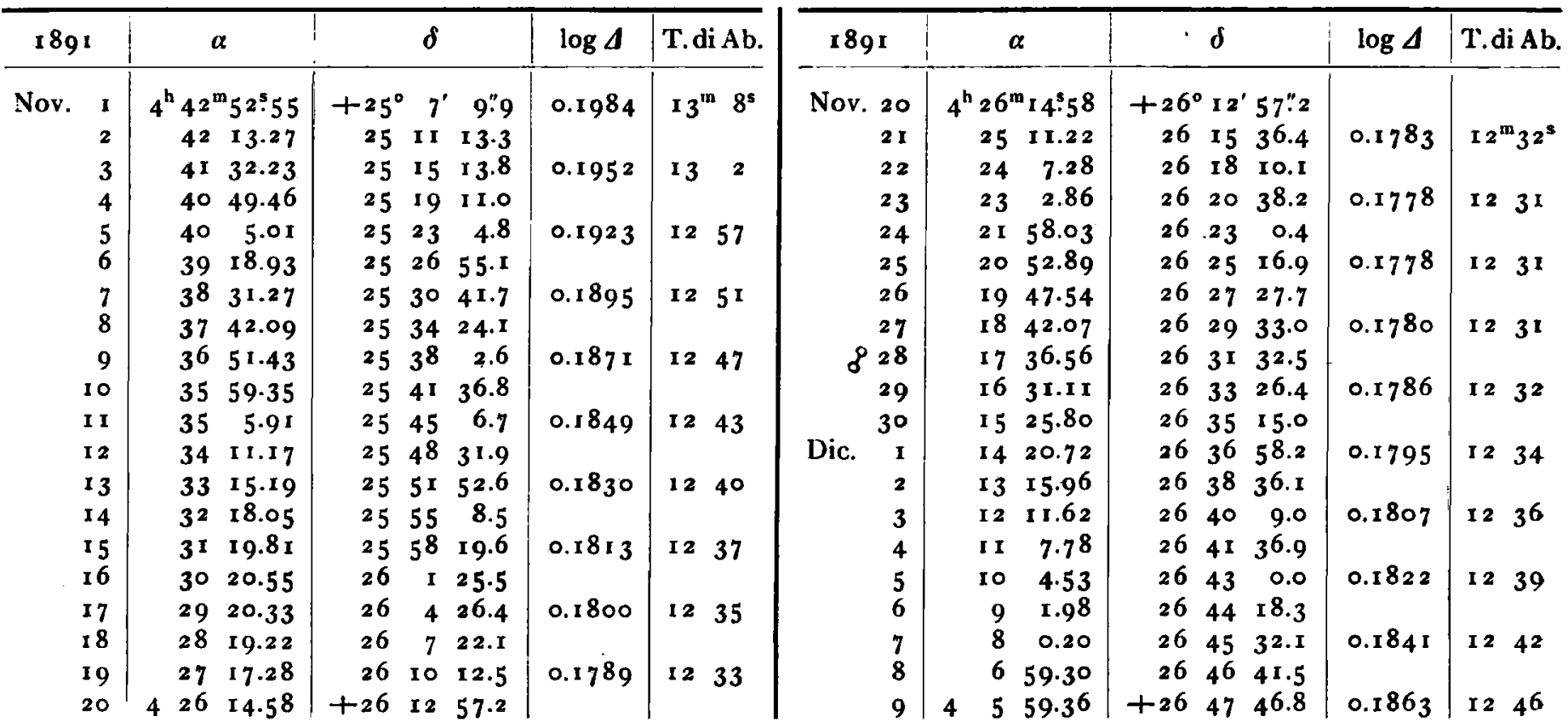

Teramo 189 I Ottobre.

Opposizione in AR. Novembre 28. Grandezza $=11.5$.

\begin{tabular}{|c|c|c|c|}
\hline $189 \mathrm{I}$ & $\alpha$ app. & $\delta$ app. & $\log \Delta$ \\
\hline Nov. 9 & $23^{\mathrm{h}} \times 1^{\mathrm{m}} 6^{\mathrm{s}} \mathrm{I}$ & $-7^{\circ} 20^{\circ} 27^{\prime \prime}$ & $\cdot 0.0820$ \\
\hline $\begin{array}{l}13 \\
17\end{array}$ & $\begin{array}{rr}14 & 29.3 \\
18 & 6.2\end{array}$ & $\begin{array}{rrr}7 & 1 & 38 \\
6 & 39 & 56\end{array}$ & $\begin{array}{l}0.0966 \\
0.1112\end{array}$ \\
\hline 21 & $22 \quad 5.0$ & $\begin{array}{lll}6 & 1533\end{array}$ & 0.1257 \\
\hline 25 & 2624.1 & $\begin{array}{lll}5 & 48 & 3^{8}\end{array}$ & 0.1400 \\
\hline 29 & $\begin{array}{llll}23 & 31 & 1.9\end{array}$ & $-5 \quad 1925$ & 0.1542 \\
\hline
\end{tabular}

\section{Elemente des Planeten (315) (Palisa Sept. 4).}

Die Elemente sind berechnet aus Wien Sept. 4, 24 und Oct. 6.

Epoche $18 \mathrm{gr}$ Sept. 4.5 M. Z. Berlin.

$$
\begin{aligned}
& M=4^{\circ} 3^{1} \quad 0^{\prime \prime} 3 \\
& \omega=178 \quad 3252.7 \\
& \delta=1605532.3 \text { M. Aequ. } 189 \text { ז.0 } \\
& \varphi=9^{\circ} 3 I^{\prime} 53^{\prime \prime} 3 \\
& \mu=1076.73^{\circ} \\
& i=2190.1
\end{aligned}
$$

$\mathbf{I}^{\text {h }}$ M. Z. Berlin.

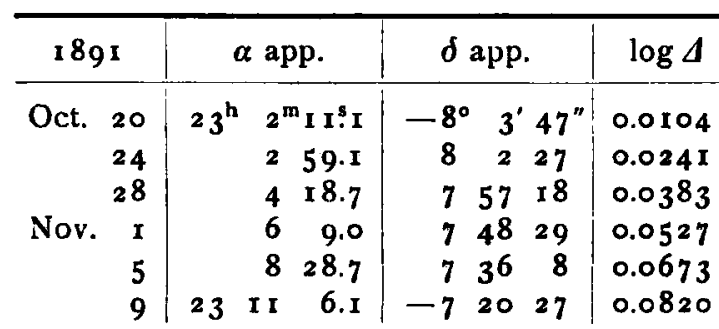

Berlin 1891 Oct. 19.
Karl Bohlin. 